\title{
РЫНОК ИПОТЕЧНОГО КРЕДИТОВАНИЯ В УСЛОВИЯХ ПАНДЕМИИ COVID-19
}

\author{
(c) 2021 Пшеничнов Руслан Владимирович \\ начальник службы по развитию партнерского канала продаж \\ АО Россельхозбанк, Респ. Марий Эл, Йошкар-Ола \\ E-mail: psheni4nov@yandex.ru
}

(c) 2021 Бурков Алексей Владимирович

доктор экономических наук, профессор кафедры прикладной статистики и информатики, Марийский государственный университет, Респ. Марий Эл, Йошкар-Ола

E-mail: alexey.burkov@gmail.com

\begin{abstract}
Работа выполнена при финансовой поддержке РФФИ в рамках научного проекта № 20-01000472 А «Методология применения систем распределенных реестров (технологии блокчейн) в обеспечении экономической безопасности субъектов ипотечного кластера»
\end{abstract}

Современная экономика еще не сталкивалась с таким глобальным явлением как пандемия, вызванная вирусом COVID-19. Пандемия повлияла не только на уровень спроса, но и в целом на его структуру. В связи с карантином, удаленное обслуживание стало неотъемлемой частью жизни для большинства граждан нашей планеты. В связи с этим столь важно данное исследование, анализирующее текущее состояние рынка ипотечного кредитования, его лидеров и дальнейшие тенденции развития. Государственные программы, реализуемые правительством в сфере ипотеки, несомненно помогли скорейшему восстановлению и многие банки стремились этим воспользоваться для увеличения доли рынка. В условиях низких ставок, смягчения требований для ипотечных заемщиков и ограничения производственных мощностей цены на недвижимость резко повысились. В статье авторы приводят анализ основных тенденция на рынке ипотечного кредитования и приводят полученные ими выводы.

Ключевые слова: ипотека, банки, кредиты, COVID-19, анализ рынка, дескриптивная статистика, пандемия.

Потребности современного человека сложно реализовать без привлечения современных финансовых инструментов. Одним из таких инструментов является ипотечное кредитование, которое прочно вошло в современную жизнь. Во многом это связано с тем, что приобретение жилья является базовой потребностью каждого человека. Финансовая система, реагируя на данную потребность, предлагает каждый год новые варианты и условия приобретения жилья в рамках ипотечного кредитования, делая ипотеку более доступной и привлекательной для широкого круга лиц. COVID-19 внес форс-мажорные обстоятельства во все финансово-экономические сферы. Сфера ипотечного кредитования не стала исключением. Напротив, институт ипотеки в период пандемии претерпел некоторые модификации. Остановимся на некоторых тенденциях 2020 года в деятельности крупнейших банков России, результаты реализации которых мы можем наблюдать в 2021 году.
Можно отметить, что в 2020 году сфера ипотечного кредитования претерпела трансформацию на фоне общего снижения ВВП на 3,1\%. Одним из аспектов ипотечного кредитования этого периода стали правительственные меры финансовой поддержки банковской сферы в целом и сферы ипотечного кредитования в частности. Так, были выделены финансовые ресурсы для обеспечения льготной ипотеки для приобретения жилья (стоимость ипотечного жилья в Москве и Санкт-Петербурге была ограничена 8 млн. рублей, в других городах -3 млн. рублей).

По условиям «Льготной ипотеки» ставки не должны были превышать 6,5\% (рис. 1). По отдельной категории кредитов под названием «Семейная ипотека» ставка должна была сохраняться ниже 6\%. Ставки ипотечных кредитов на уровне $6,5 \%$ сохраняли все ведущие банки, осуществляющие ипотечное кредитование, в том числе: ПАО «Банк Уралсиб», АО «ЮниКредит Банк», 
РНКБ Банк (ПАО) и «Азиатско-Тихоокеанский Банк» (АО), АО «Банк ДОМ.РФ». Средняя ставка среди банков в 2020 году держалась на уровне 6,16\%. В рамках программы «Семейная ипотека» ставка по кредиту в среднем составляла 5,04\% годовых. Максимальные 6\% по данному виду ипотеки предлагалась АО «ЮниКредит Банк» и РНКБ Банк (ПАО). Минимальный порог отмечен на уровне 4,5\% в коммерческом банке ПАО КБ «Центр-инвест».

Данная мера государственной поддержки получила эффект в виде 35\% ипотечного кредитования в секторе розничных кредитов с соответствующим ростом ее объемов [3]. С одной стороны, увеличилось количество и объемы ипотечного кредитования, а с другой стороны начали расти цены на жилую недвижимость. Последнее является негативным фактором, т.к. увеличивает «закредитованность» населения, снижая эффективность реализации мер государственной поддержки.

Рассматривая ипотечные ставки по кредитам, предоставляемым не в рамках государственных программы и в разрезе категории рынка жилья можно отметить, что ставка превышала 9\% как на ипотечном рынке первичного жилья, так и на вторичном рынке жилья, и при рефинансировании первичного кредита (рис. 2). Среди банков, предлагавших наивысшую ставку можно отметить АО «Газпромбанк» и РНКБ Банк (ПАО). В рассматриваемом периоде АО «Банк ДОМ.РФ» предлагал минимальные
7,3\% на кредиты по первичному рынку, что показательно, так как данная кредитная организация является опорным кредитором в период перехода к эскроу-финансированию и отказа от долевого [4]. Рассматривая максимальную и минимальные ставки можно отметить, что разница между ними незначительна - 1,7\%. Среднюю ставку в 8,22\% выдержали банки: ПАО ВТБ, АО «Россельхозбанк», АО «Альфа-Банк», АО «Райффайзенбанк», АКБ «Абсолют Банк» (ПАО), ПАО «Банк Уралсиб», ТКБ Банк ПАО, «АзиатскоТихоокеанский Банк» (АО).

Для вторичного рынка характерна картина с более высокими кредитными ставками. Это следствие уже давно изученной тенденции: государство заинтересовано прежде всего в развитии строительной отрасли и соответственно стимулирует кредитование приобретения недвижимости на первичном рынке. Банки также заинтересованы привлечь как можно больше потребителей, сотрудничают в ряде случаев с застройщиками в отношении целых жилых кварталов, снижая ставки по ипотеке [5]. Приобретение в ипотеку вторичного жилья является более редким вариантом по сравнению с рынком первичной недвижимости и соответственно диктует более высокие ставки по ипотеке. Так в 2020 году на рынке вторичного жилья ПАО «Совкомбанк» выдавал кредиты по ставке 9,89\%, а АО «ЮниКредит Банк» - по ставке 7,4\% и это была наименьшая ставка по ипотеке вторичного рынка. Средний размер ставки на данном рынке

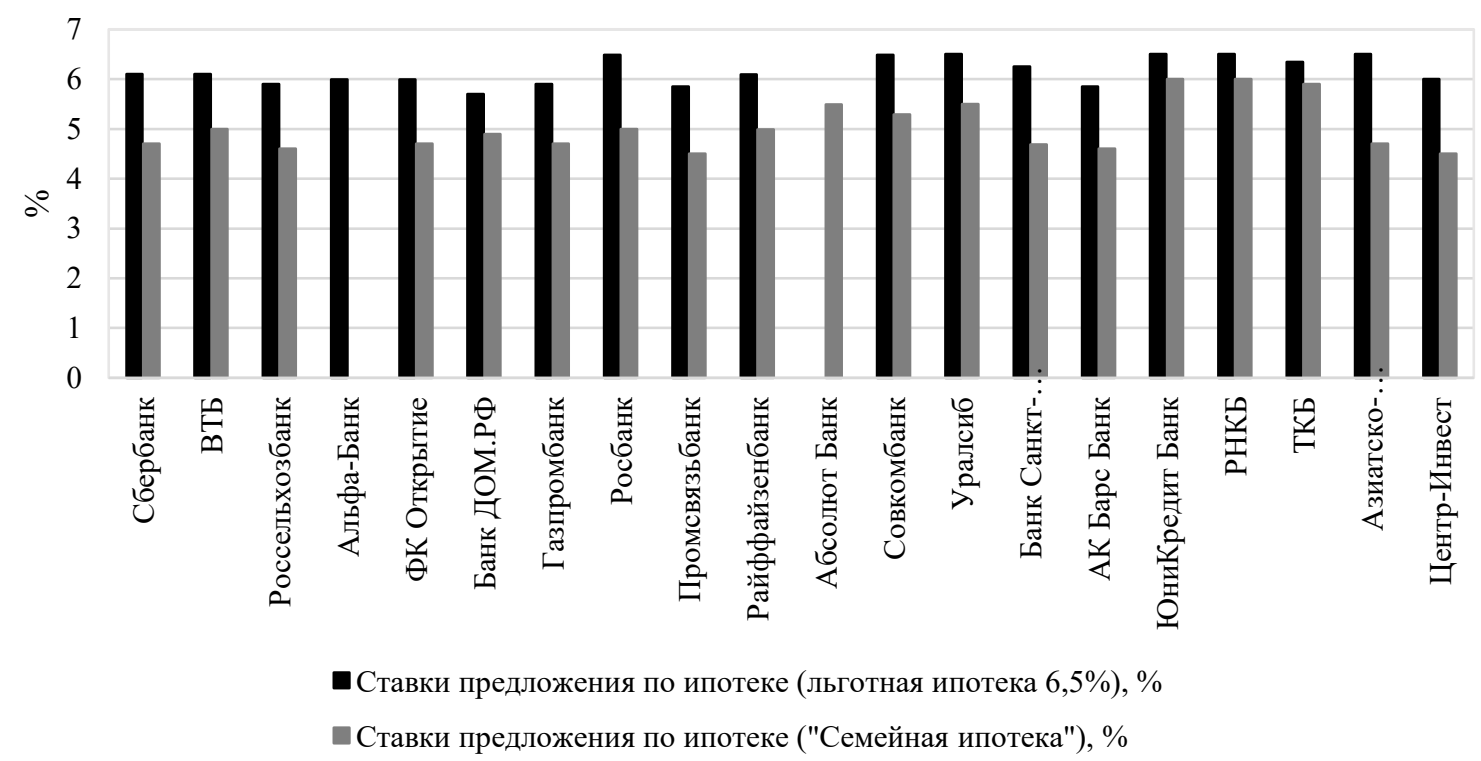

Puc. 1. Ставки предложений по «Льготной ипотеке (6,5\%)» и по «Семейной ипотеке» ведущими банками РФ за 2020 год [6] 


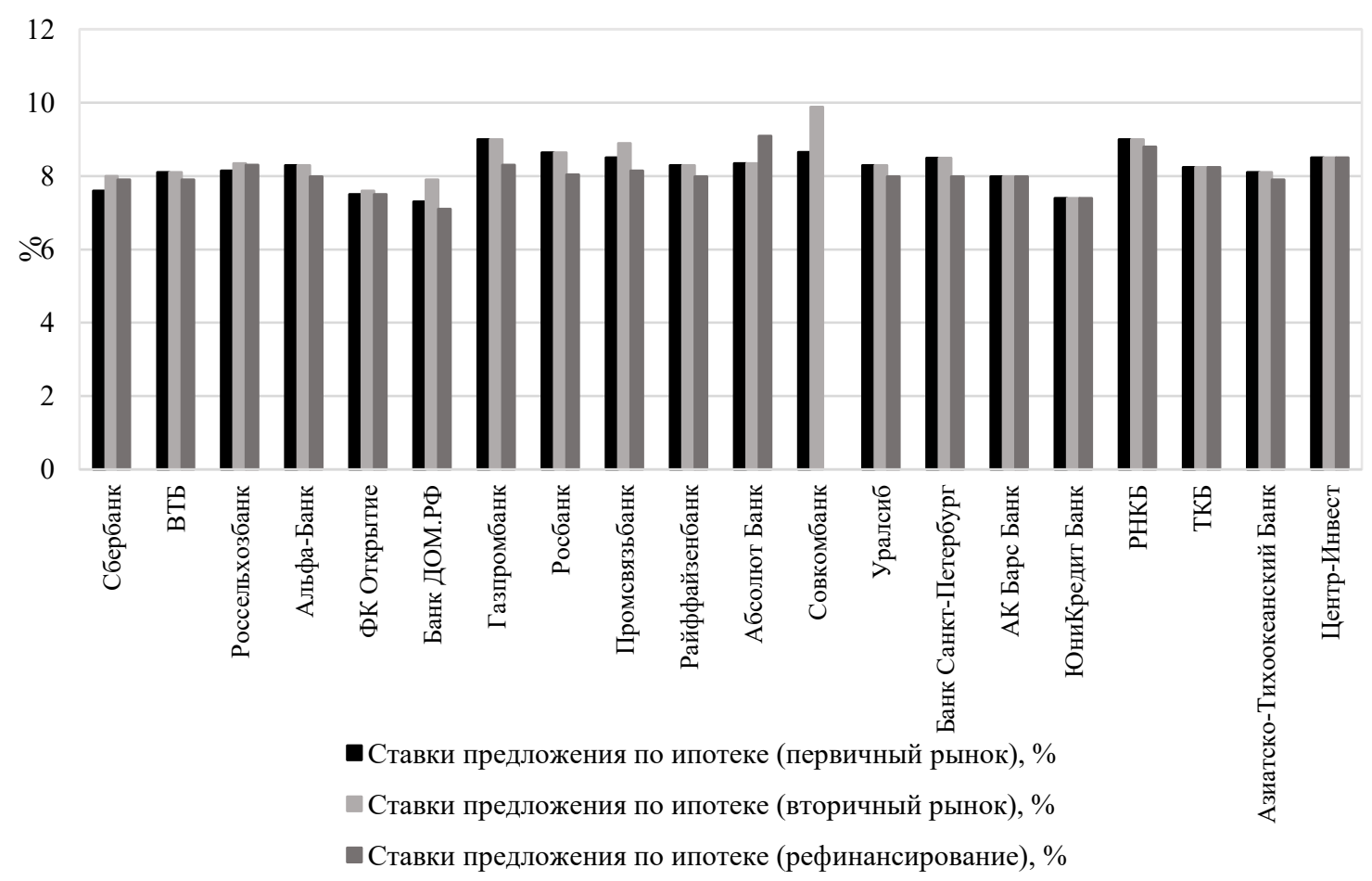

Puc. 2. Ставки предложений по ипотеке на первичном, вторичном рынках и на рефинансирование ведущими банками РФ за 2020 год [6]

составил 8,37\%, в том числе у таких банков, как АО «Россельхозбанк», АКБ «Абсолют Банк» (ПАО), ПАО «Банк Уралсиб», АО «Райффайзенбанк», АО «Альфа-Банк».

Рассмотрим динамику объема выданных ипотечных жилищных кредитов в 2019-2021 гг. (рис. 3). Со второго полугодья 2019 года объемы ипотечных кредитов начали уверенно расти (если в мае 2019 г. эта цифра составляла 192 млрд. руб., то к концу декабря 2019 г. объем кредитов составил 370 млрд. руб.). Основную массу составили рублевые кредиты.

В начале 2020 года укрепилась тенденция к росту объемов выдачи ипотечных кредитов, но ситуация с локдауном внесла свои коррективы и с мая 2020 г. темпы кредитования сократились на 34\%. Введение программы льготной ипотеки выступило стимулом ипотечного кредитования до ноября 2020 году и дальше вплоть до июля 2021 года регистрировалось увеличения объемов данного вида кредита.

Как мы уже отметили, рост объемов выданных кредитов увеличил объем задолженности по ипотечному кредитованию (рис. 4). На конец указанного периода размер задолженности достигал 9,5 трлн. руб. На фоне роста задолженности продолжался рост просроченной задолженности.

Рассматривая рынок ипотечного кредитова- ния в разрезе субъектов ипотечных отношений можно выделить стойкую тенденцию: разные регионы характеризуются различным уровнем доходов и соответственно различным потенциалом населения к ипотечному кредитованию. Так, среди лидеров по объемам ипотечного кредитования выступают Центральный федеральный округ, Приволжский и Северо-Западный федеральные округа. Тем не менее, ипотечный рынок всех остальных округов также характеризуется положительной динамикой.

На начало 2021 года среди банковучастников рынка ипотечного кредитования можно было выделить 280 кредитных организаций. Статистическое агентство FRANK RG среди крупнейших банков на ипотечном рынке выделяет два банка - Сбербанк и ВТБ [7], которым принадлежит до 70\% ипотечного профиля страны. Оставшуюся долю рынка делят между собой остальные банки. Так, Газпромбанк $-3,9 \%$, Россельхозбанк - 3,6\%. Другие банки занимают небольшие оставшиеся доли рынка.

Проведя анализ информации по ипотечным кредитам двадцати банков - лидеров этого сектора кредитования за 2020 год с использованием показателей положения, показателей разброса, показателей асимметрии, показателей распределения, были сделаны следующие выводы.

Во-первых, в 2020 году максимальный объем 


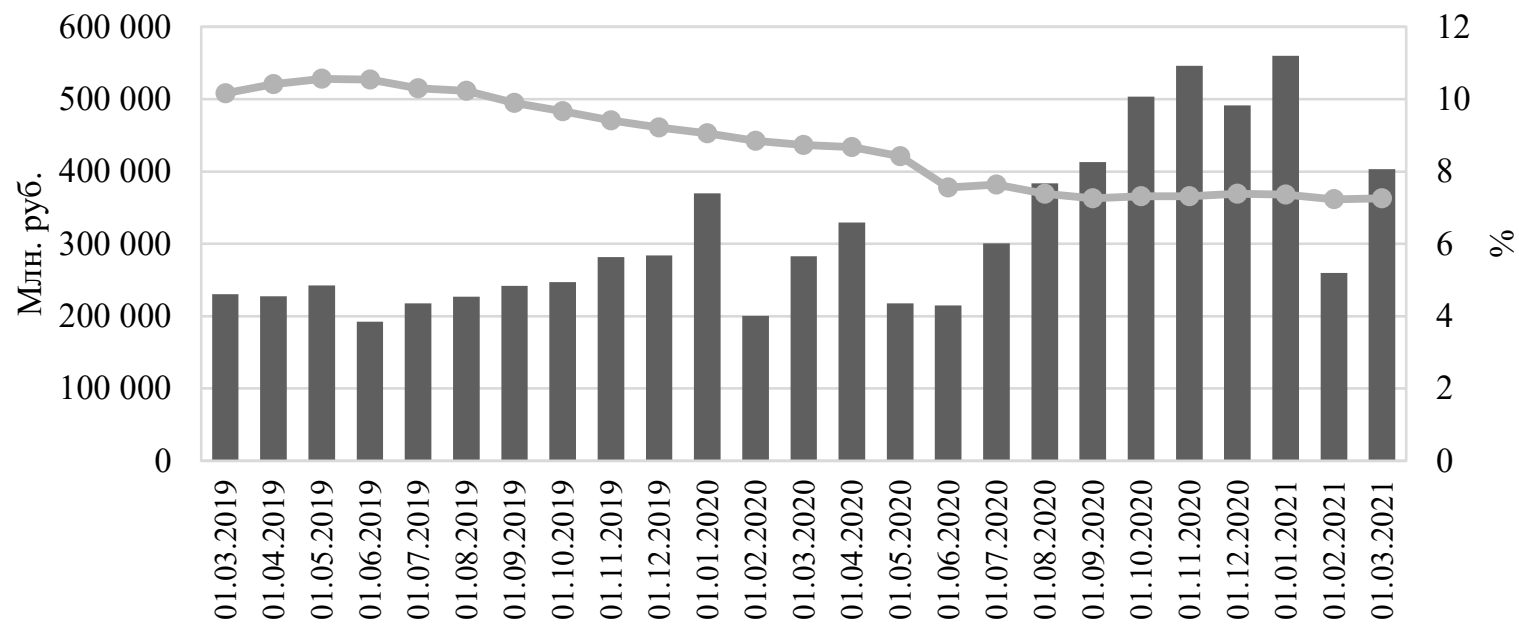

Ипотечные жилищные кредиты, предоставленные за месяц в рублях, млн. руб.

- Средневзвешенная ставка по ИЖК в рублях, предоставленных за месяц, \%

Рис. 3. Динамика объема предоставленных ипотечных кредитов (февраль 2019 г. - февраль 2021 г.)

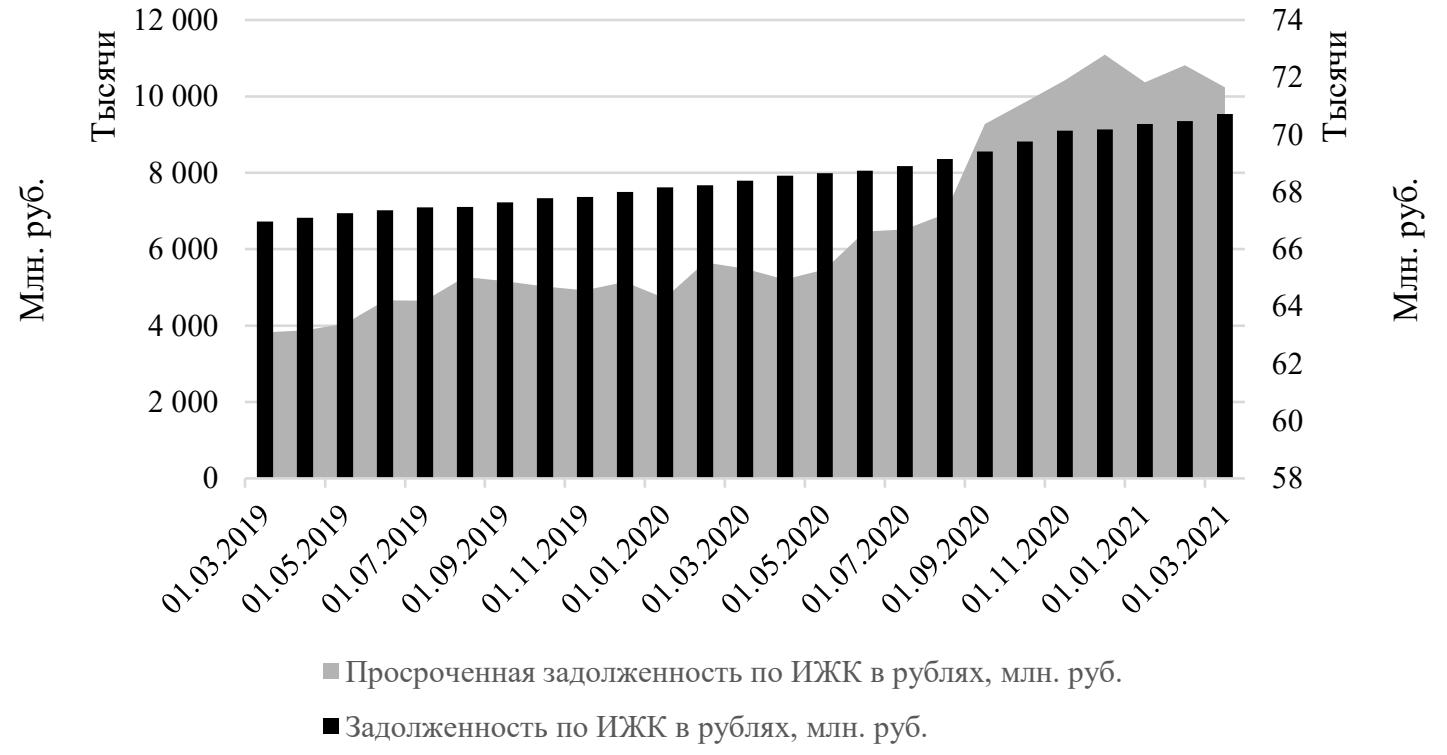

Pис. 4. Динамика задолженности по ипотечным жилищным кредитам (февраль 2019 г. - февраль 2021 г.)

ипотечных кредитов предоставил ПАО «Сбербанк» на сумму 2,8 трлн. руб. Минимальный ПАО КБ «Центр-инвест» на сумму 14,1 млрд. руб. Показатель размаха составил 2,07 трлн. руб., а если брать средний размер, то он составил 214,67 млрд. руб., то есть объемы ипотечных жилищных кредитов в различных банках сильно отличались (коэффициент вариации, например, превысил нормативное значение почти в 7 раз).

Во-вторых, ПАО Сбербанк сохраняет лидерские позиции как ипотечный банк России, в частности по количеству и объему выданных ипотечных жилищных кредитов, числу рассмо- тренных заявок. На наш взгляд это свидетельствует о недостаточно развитой конкуренции на данном рынке, а значит отчасти о незрелости самого рынка ипотечного кредитования.

В-третьих, анализ процентных ставок по ипотеке показал, что ставки на вторичное жилье выше, чем на первичное. Государственная поддержка ипотечного кредитования присутствует именно на рынке ипотеке первичного жилья. Как следствие, вариант приобретения жилья диктуется не личными предпочтениями заемщиков, а скорее финансовыми условиями предоставляемой ипотеки. 


\section{Библиографический список}

1. Бурков А.В., Пшеничнов Р. В. Сравнительная характеристика рынка ипотечного жилищного кредитования в России и Марий Эл // Вестник Поволжского государственного технологического университета. Серия: Экономика и управление. 2020. № 3 (47). С. 89-99.

2. Выгодно ли рефинансировать ипотеку? [Электронный ресурс] // Журнал ДомКлик. URL: https://blog. domclick.ru/post/vygodno-li-refinansirovat-ipoteku (дата обращения: 15.12.2020)

3. Доклад об экономике России: декабрь 2020: [Электронный ресурс] // Русипотека: кредитование и секьюритизация. URL: http://rusipoteka.ru/files/analytics/worldbank/doklad-ob-ekonomike-rossii-44.pdf (дата обращения: 15.12.2020)

4. ДОМ.РФ [Электронный ресурс]. - Режим доступа: https://дом.рф/ (дата обращения: 07.01.2021)

5. Обзор рынка ипотечных облигаций в 2020 году: [Электронный ресурс] // ДОМ.PФ. URL: https://дом.pф/ upload/iblock/c8f/c8f11e1f5836be8bb35ddaa9dec78440.pdf (дата обращения: 27.12.2021)

6. Топ-20 ипотечных банков: итоги 2020 года: [Электронный ресурс] // FRANK.RG. URL: https://дом.pф/ upload/000/Ipotechnye_banki.pdf (дата обращения: 27.12.2020)

7. FRANK.RG [Электронный ресурс]. - Режим доступа: https://frankrg.com/data-hub/category/mortgage (дата обращения: 27.12.2020) 